\title{
Los recogimientos, de centros de integración social a cárceles privadas: Santa Marta de Quito
}

M. ${ }^{a}$ Isabel Viforcos Marinas

Universidad de León

Se trata de una aportación al conocimiento de las casas de recogidas del Nuevo Mundo, a través del recogimiento quiteño de Santa Marta. Fundado por don Luis López de Solís en 1595 para que sirviera de centro educativo para las huerfanas, de reformatorio para las mujeres de vida escandalosa y de refugio honesto para las que se hallaban en proceso de separación matrimonial, se vería abocado, por las estrecheces económicas, la falta de apoyo institucional y el cambio de mentalidad, a transformarse en cárcel privada de mestizas e indias, forma en la que perviviría hasta la época de la Independencia.

El presente trabajo no pretende ser sino una aportación, a través del estudio del recogimiento quiteño de Santa Marta, al conocimiento de la evolución experimentada por las más de las casas de recogidas del Nuevo Mundo, abocadas a desaparecer al poco tiempo de su instauración o a transformarse, perdiendo su primitivo y genuino carácter de centros de integración social, bien en beaterios o claustros conventuales, bien en instituciones de represión, como ocurre con la que vamos a analizar.

\section{El obispo Luis López de Solís y sus inquietudes fundacionales}

Entre la ingente labor desarrollada por el prelado salmantino Luis López de Solís en pro de la diócesis quiteña, para la que fue preconizado por Clemente VIII en 1592, merece destacada y especial mención su actividad fundacional, íntimamente vinculada a su celo pastoral, a su constante preocupación por la promoción huma- 
na del indio y a sus inquietudes culturales. ' Con su aliento, y en ocasiones con su directa promoción y financiación, fueron surgiendo diversos centros educativos masculinos: escuelas primarias en los poblados y repartimientos de indios para enseñar a leer y escribir a los hijos de caciques y principales; el colegio-seminario de San Luis en Quito, con su anejo para hijos de caciques; y, tras la aprobación por el Consejo de la bula institucional expedida por Sixto $\mathrm{V}$ en 1586 , el primer centro universitario quiteño, erigido en el convento agustiniano bajo la advocación de San Fulgencio. ${ }^{2}$

Tampoco desatendió el prelado la educación femenina. De acuerdo con la mentalidad de la época, la formación de la mujer debía ir orientada o al matrimonio y la matemidad, o a la vida religiosa. Su enseñanza debía limitarse pues a la doctrina cristiana, las prácticas religiosas, las labores manuales y el cultivo de alguna actividad musical, con frecuente descuido de la alfabetización. Los franciscanos fueron los pioneros de la enseñanza de las indígenas, comenzando por reunir en los patios de sus conventos a indias, nobles y plebeyas, que aprendían bajo la tutela de alguna beata, y pasando pronto, a partir de la fundación del colegio de Texcoco (1529), al régimen de internado. Sin embargo, la encomiable labor del obispo Zumárraga y sus franciscanos en el México central tendría que abandonarse a mitad del siglo XVI a causa de la oposición de los propios indios, que se resistían a que sus hijas ingresasen en los recogimientos y rehuían el casarse con mujeres educadas en ellos.

1 Sobre la figura y actividades del prelado don Luis López de Solís remitimos, además de a las ya clásicas aportaciones de R. Vargas Ugarte (Historia de la Iglesia en el Perú, T. II, Burgos, 1959, especialmente págs. 158-160, 270-273 y 352-355), y J. M. " Vargas (El gobierno episcopal del Ilmo. fray Luis López de Solis, "Archivo Agustiniano", vol. XLVIII, Madrid, 1954, pág 205 y ss.), a los estudios de F. Campo del Pozo (Los sínodos de fray Luis Lopez de Solis y el clero indígena, "Archivo Agustiniano", vol. LXXV, Valladolid, 1991, págs. 87-114), F. Carmona Moreno, (Acción Pastoral de Luis Lopez de Solís, Real Monasterio de El Escorial, 1980 y Fray Luis Lopez de Solís, O.S.A. y su fundación del seminario de San Luis de Quito, 1594, "Agustinos en América y Filipinas. Actas del Congreso Internacional", Vol. II, Valladolid-Madrid, 1990, págs. 899-911) y S. Folgado Flórez (Fr. Luis López de Solís o la lógica de un quehacer evangelizador (1534-1606), "Evangelización en América. Los agustinos", Salamanca, 1988, págs. 61-102).

2 Egaña, A. de: Historia de la Iglesia en la América Española. Hemisferio Sur, Madrid, 1961, pág. 434 y ss. Folgado Flórez, Fray Luis López de Solís.... 
Aunque los centros educativos de indias no desaparecieron del todo, como lo prueba la fundación en 1546 del beaterio guatemalteco de la Orden del Rosario, la educación de la mujer indígena quedó prácticamente olvidada en el Nuevo Mundo, centrándose toda la atención en las españolas - tanto peninsulares como criollas- y en las mestizas. Puesto que hasta la fundación en 1754 de los colegios de la Compañía de María no hubo una institución dedicada específicamente a tareas educativas, la principal modalidad de enseñanza, aunque también existió la particular de "las amigas", fueron los monasterios de monjas y las casas de recogimiento. Esta función refuerza la dimensión social de las fundaciones monacales femeninas en el ámbito colonial. El claustro ofrece a su fundador y financiador la posibilidad de perpetuar su memoria y descargar su alma, a la mujer soltera o viuda la única salida digna para su honra y la mejor vía de santificación para su espíritu, y a la comunidad urbana en la que se inserta sus servicios religiosos y educacionales, además de convertirse en timbre de notoriedad para la ciudad que lo acoge. ${ }^{3}$

Durante la prelatura de don Luis, la diócesis quiteña se beneficiaría de un considerable aumento de monasterios femeninos: el de Santa Clara y el de Santa Catalina en Quito, y los de la Concepción en Cuenca, Loja y Riobamba. ${ }^{4}$ Pero, sin duda, la fundación más singular por su peculiar carácter fue la de Santa Marta, emprendida en los últimos años del siglo XVI en la capital del obispado.

3 Acerca de la educación femenina y del papel de los monasterios de monjas remitimos a: Borges, P.: Misión y Civilización en América, Madrid, 1987; Foz y Foz, P.: La revolución pedagógica en Nueva España (1754-1820), vol. 1, Madrid, 1981, especialmente págs. 197-204; Gonzalbo Aizpuru, P.: La educación en la época colonial. El mundo indigena, México, 1990; Gómez Canedo, L.: La educación de los marginados durante la época colonial. Escuelas y colegios para indios y mestizos en la Nueva España, México, 1982, especialmente págs. 93-130, 307-314; Merlo Juárez, E.: Las concepcionistas primeras educadoras en México, "La Orden Concepcionista. Actas del I Congreso Internacional", vol.I, León, 1990, págs. 485-500; Zamora, H.: Educación franciscana del indígena americano, "Actas del I Congreso Internacional sobre los Franciscanos en el Nuevo Mundo", Madrid, 1987, páginas 251-292.

4 Aunque no es mucho lo que se conoce acerca de estas fundaciones, existen ya algunas valiosas aportaciones como la del profesor Paniagua Pérez, J.: Los monasterios concepcionistas en la Audiencia de Quito. Notas para su estudio, "La Orden Concepcionista. Actas...", vol. I, págs. 563-584. 
No era ésta la primera casa de recogimiento que se intentaba fundar en aquellas tierras. Ya en 1550 fray Domingo de Santo Tomás, en un memorial dirigido a Felipe II, exponía la conveniencia de que se atendiese con prontitud a la educación femenina, fomentando en las principales ciudades del Perú - "como es en Los Reyes, Cuzco, La Villa de La Plata y Quito" - la institución de recogimientos "donde hubiese dos o tres mujeres viejas de buen ejemplo que tuviesen cargo de las niñas, de doctrinarlas en las cosas de la fe, enseñarles a coser, labrar, buenas costumbres". ${ }^{5}$ La voz del futuro obispo de Charcas encontró eco en el sevillano don Hernando de Santillán. oidor de la Audiencia de Lima desde 1548, y nombrado en septiembre de 1563 presidente de la recién creada Audiencia de Quito. Prácticamente nada más asumir su nuevo cargo, antes incluso de haber llegado a la capital quiteña, inició las gestiones para obtener la licencia real necesaria a fin de que pudiera erigirse "una casa de recogimiento donde se recogiesen muchas doncellas pobres, mestizas y españolas, hijas de conquistadores". Sin embargo, Santillán abandonaba el Nuevo Continente en 1568 sin que la fundación se hubiese hecho realidad, bien porque sus inquietudes no supieron despertar el interés de Felipe II, bien porque sus fuerzas se agotaron en hacer realidad la monumental obra de beneficencia del Hospital de la Caridad, aunque es posible que en su fracaso fundacional influyesen también las tensiones con el obispo quiteño Pedro de La Peña. ${ }^{6}$

La creación de los primeros monasterios femeninos en la ciudad de San Francisco acaparó la atención y los esfuerzos de la sociedad quiteña en los años siguientes. En 1575 el obispo de la Peña iniciaba las gestiones para la fundación de las Concepcionistas, que se haría realidad dos años más tarde; la iniciativa de doña María de Siliceo y de doña Francisca de Cueva lograría en la última década del siglo la erección de los monasterios de Santa Catalina de Sena y Santa Clara, respectivamente. Sin embargo, estas tres fundaciones

\footnotetext{
5 Vargas, J.M.: Historia del Ecuador. Siglo XVI, Quito, 1977, pág. 190.

6 Ibidem y Egaña, Historia de la Iglesia en la América Española..., págs. 366, 417 y 425 .
} 
sólo ofrecían una respuesta parcial, y por tanto insuficiente, a las necesidades educacionales, morales y socioeconómicas de aquellos tiempos. La rápida saturación de los claustros, la necesidad de contar con una dote de ingreso y las cortapisas étnico-sociales presentes en la mayoría de las reglas y constituciones seguían haciendo necesario otro tipo de centro de acogida para las mujeres, más flexible y abierto. Resurge así en 1595 la idea de crear en Quito un recogimiento, el de Santa Marta, al estilo de los que venían proliferando desde las décadas anteriores en México - Recogimiento de Jesús de la Penitencia, Hospital de la Misericordia, Emparedamiento de Santa Mónica-; en la ciudad de Cuzco — San Juan de Letrán- o del que patrocinaba en Lima la Hermandad de la Caridad y de la Misericordia bajo la advocación de San Juan de la Penitencia. ${ }^{7}$

\section{Los primeros tiempos del recogimiento quiteño}

Nació Santa Marta, de acuerdo con los testimonios de don Francisco de Mendoza Manrique, lugarteniente del virrey García Hurtado de Mendoza, y del padre Onofre Esteban, predicador de la Compañía de Jesús, en junio de $1595 .{ }^{8}$ Según la información practicada en Quito a comienzos de 1600, en cumplimiento de la cédula real despachada en San Lorenzo del Escorial a 12 de agosto de 1598, la iniciativa fundacional había partido de Alonso de Moreta y su mujer, doña Francisca Bernal, vecinos de Quito, los cuales habían donado unas casas de su propiedad para construir en ellas una capilla y establecer un recogimiento femenino, todo ello con la aquiescencia del obispo don Luis López de Solís, bajo cuyo patronazgo se colocó la fundación. ${ }^{9}$

La casa de Santa Marta se creaba con la triple finalidad de servir de reformatorio para las mujeres de vida escandalosa y disolu-

7 Egaña, Historia de la Iglesia en la América Española..., pág 58; Muriel, J.: Los recogimientos de mujeres, México, 1974 y Vargas Ugarte, Historia de la Iglesia en el Perú..., págs. 347-352 .

8 AGI, Quito, 76, fols. 783 y 792.

9 Ibídem, fols. 777-780 y Jiménez de la Espada, M. (ed.): Relaciones Geográficas del Perú, "Relación de Diego Rodríguez Docampo", T. III, Madrid, 1965, pág. 10. 
ta, de refugio honesto y seguro para aquellas casadas que se hallaban inmersas en procesos de separación matrimonial y de centro de educación para huerfanas mestizas y descendientes de conquistadores. Era pues una fundación mixta, en la medida en que participaba del doble carácter de centro de ayuda para la mujer que a ella acudía de modo voluntario en busca de protección para su honra y formación para tomar estado, y de lugar de reclusión y castigo para las condenadas por la justicia a causa de su vida licenciosa.

Para tan ambicioso objetivo, la nueva fundación no contaba con más medios que el solar y casa donada por el citado Alonso de Moreta y la caridad de fray Luis, que con ser mucha, apenas alcanzaba para cubrir las multiples obras educacionales, asistenciales y pastorales a su cargo. ${ }^{10}$ Por ello el obispo solicitó al rey que, en consideración a los grandes beneficios morales y espirituales que se derivarían de la nueva casa, dotase a ésta con dos mil pesos de renta en indios vacos. Felipe II respondía a la solicitud episcopal con la mencionada cédula de 1598 , en virtud de la cual se encargaba al presidente y oidores de la Audiencia de Quito la elaboración de un informe sobre la necesidad y utilidad del recogimiento, así como de los bienes en que se podrían fundar sus rentas sin acudir a los recurrentes repartimientos de indios. ${ }^{11}$

La prueba testifical sobre la que se basó la relación elaborada por la Audiencia se inició a principios de febrero del año 1600, muy pocos días antes de que tomase posesión de la presidencia del alto tribunal el licenciado Miguel de Ibarra. El cuestionario base de la información constaba de siete preguntas: La primera se refería a las condiciones personales de los testigos llamados para la probanza y

10 Según los datos ofrecidos por Esteban Marañón en la relación de las rentas de la catedral y el obispado de Quito elaborada en 1598, las rentas episcopales superaban los seis mil pesos (Ponce Leiva, P.: Relaciones Histórico-Geográficas de la Audiencia de Quito (Siglo XVI-XIX), T.I, Madrid, 1991, págs. 575-577). Dichos ingresos solían ser divididos por el obispo Solís en cuatro partes: tres de ellas las destinaba para sostener la fábrica de las iglesias y socorrer a los más pobres; la parte que restaba la subdividía en otras tres, de las cuales sólo una tercera parte dedicaba al sustento de su persona y familia, reservando las otras dos para atender gastos y. socorros extraordinarios de personas necesitadas (Folgado Flórez, Fray Luis López de Solís..., pág. 85).

11 AGI, Quito, 76, fol. 777. 
a su relación con las partes implicadas en ella; la segunda iba dirigida a clarificar las circunstancias de la fundación y sus motivaciones; las tres cuestiones siguientes estaban orientadas a determinar hasta qué punto existía en la ciudad de Quito necesidad de un centro femenino de recogida, inquiriendo sobre la cantidad de mujeres de vida licenciosa, la frecuencia con que se suscitaban procesos de separación y la situación de las implicadas en ellos, y la conveniencia de un centro educacional para formar a las niñas huerfanas, particularmente a las mestizas; las dos últimas preguntas se centraban en la descripción del edificio que albergaba la fundación y en el estado económico de la misma. El cuestionario se cerraba con el juramento y ratificación de testimonios de cada uno de los personajes interrogados. ${ }^{12}$

Fueron llamados a consulta ocho testigos, en su mayoría eclesiásticos. Los únicos seglares fueron don Diego de Portugal y don Francisco de Mendoza y Manrique. El primero era sobrino del que fuera virrey de Perú entre 1585 y 1589, don Fernando Torres Portugal y Mesía, conde del Villardonpardo, y había sido nombrado corregidor de Quito por don Luis de Velasco el 12 de mayo de 1597. No llevaba demasiado tiempo en la ciudad del Pichincha - apenas dos años y medio- cuando se realizó la probanza, pero su cargo le habilita como cumplido conocedor tanto del clima de relajación moral con el que se pretendía justificar la fundación, como de los beneficiosos efectos de la obra promovida por el obispo Solís, con el que, por otra parte, coincidía en sus tensas relaciones con la Audiencia y su presidente Ibarra. ${ }^{13}$ El segundo, don Francisco de Mendoza, residía en Quito desde hacía unos seis años, razón por la cual conocía el recogimiento desde su gestación. Por los méritos demostrados como general de la armada que en 1575 había transportado el tesoro real desde Lima a Tierra Firme y como asentador de las alcabalas en Cuzco, fue designado primer corregidor de Quito por el virrey don García Hurtado de Mendoza, cargo que había de-

12 Ibídem, fols. 778-780.

13 Vargas, J. M.a: El gobiemo episcopal del Ilmo. fray Luis Lopez de Solís, página 332 .

Tomo L nüm. 2, 199.3 
sempeñado junto con el de lugarteniente de capitán general para el distrito de la Audiencia. De su probidad da testimonio cumplido el propio obispo Solís, al afirmar que "dio la mejor residencia que acá se ha dado" y solicitar para él un nuevo cargo en el virreinato, tan pronto como fue sustituido en el corregimiento por don Diego de Portugal. ${ }^{14}$ Los testimonios de ambos son absolutamente coincidentes en sus apreciaciones y juicios de valor, abiertamente favorables a la pervivencia de la casa de Santa Marta y a la conveniencia de que el rey la dotara de renta suficiente para su sustento, ya que hasta entonces se había mantenido a costa del obispo agustiniano y de las voluntarias aportaciones de los vecinos. ${ }^{15}$

De los clérigos consultados, dos pertenecían al clero secular: el doctor don Miguel León y don Jorge Ramírez de Arellano. El primero era maestrescuela de la catedral, había sido juez de divorcios en Lima, razón por la que era conocedor de la Casa de Divorciadas fundada para doncellas pobres y casadas en trámites de separación, por Santo Toribio, en la capital de la archidiócesis, junto al monasterio de Santa Clara. ${ }^{16}$ Esta circunstancia, unida a su condición de confesor de la casa de Santa Marta, confiere a su declaración un especial valor. Don Jorge Ramírez de Arellano era chantre de la seo quiteña y comisario del Santo Oficio y aunque no se hallaba especialmente vinculado ni a la problemática de la mujer ni a ninguna fundación del tipo de la que nos ocupa, lo prolongado de su estancia en Quito -más de veinte años- le convierte en un buen conocedor de la ciudad y su ambiente. Las declaraciones de ambos son en todo parejas y siguen la misma tónica de las efectuadas por los representantes del poder civil. ${ }^{17}$

Los cuatro testigos restantes pertenecen a ordenes religiosas. Dos eran jesuitas: el padre Diego Alvarez de Paz, rector de la Compañía y destacado escritor ascético, y el ya mencionado padre Onofre Esteban; otro era franciscano, fray Juan de Cáceres, guardián de la casa-convento de San Pablo; y el cuarto era un agustino, fray

14 Ibidem, págs. 307-309 y 333.

15 AGI, Quito, 76, fols, 780-785.

16 Vargas Ugarte, Historia de la Iglesia en el Perú..., págs. 115-116.

17 AGI, Quito, 76, fols. 789-792r y 799v-801. 
Bartolomé Vallejo. Las respuestas del padre Diego y de fray Juan de Cáceres coinciden en su tono general, producto de la falta de conocimiento directo de la fundación, y en el favorable juicio que les merece toda obra dedicada a evitar ofensas a Dios. ${ }^{18}$ Mayor es el interés de los testimonios del padre Onofre y de fray Bartolomé, por ser las declaraciones más pasionales y las que mejor reflejan la pugna, más o menos soterrada, suscitada entre agustinos y jesuitas por las distinciones de que la Compañía era objeto por parte del obispo Solís.

El agustino fray Bartolomé Vallejo era en la época de la probanza provincial de Quito y Nueva Granada y miembro del Santo Oficio en la administración de Popayán. A pesar de su cargo, no había residido en la capital del Pichincha, en la que únicamente había estado de paso y por ello carecía de un conocimiento directo de la casa de Santa Marta. ${ }^{19}$ Esta circunstancia no le impide mostrarse abiertamente en contra de la fundación, sosteniendo que "las rentas que se deban pedir a Su Magestad para que la dicha casa de Santa Marta sea faborescida y aumentada, se debrían (sic) pedir antes para que fuesen faborescidos tres monestherios de religiosas pobres questán en esa dicha ciudad de Quito". Los alegatos esgrimidos por este fraile para justificar su postura son en síntesis cinco: ${ }^{20}$

1) Sólo si el encierro es voluntario y producto del arrepentimiento personal de las recogidas pueden seguirse de él efectos gratos a la divinidad y beneficiosos para la sociedad. Así en España, "donde tanto cuidado se tiene en escusar las ofensas de Dios", no se utilizan medios coercitivos, sino consejos y amonestaciones, por-

18 Ibidem, fols. 796v-799 y 802-804r.

19 En el "Elenco de priores y provinciales" que ofrece E. Terán en el capítulo VII de su obra el Convento de San Agustín de Quito. Síntesis Histórica como Homenaje a su IV centenario 1573-1973 (Quito, 1973), no hemos hallado referencia alguna a fray Bartolomé Vallejo. Su provincialato debió de comenzar hacia 1598 y concluir en 1601, año de la celebración del capítulo de Cali, en el que se decidió separar las provincias agustinianas de Quito y Nueva Granada, siendo elegido como provincial de la primera fray Agustín Rodriguez (Concetti, N.: Historia de la provincia de San Agustín de Quito, Quito, 1888, pág. 22).

20 Tanto las citas textuales como los argumentos pertenecen a A.G.I, Quito, 76, fols. $785 v-788$. 
que está comprobado que, "de ser compelidas, no se sigue la mejora en la virtud que se pretende".

2) Si las mujeres de mal vivir son confinadas por la fuerza, las consecuencias de su encierro serán peores que las causas que allí las condujeron. Además de aborrecer a quien las encerró, no modificarán su proceder, dando con ello un mal ejemplo a las doncellas que se estén educando en la casa y poniendo en peligro la honra de las mujeres honestas recogidas en ella. También puede ocurrir que, por evitar el rigor del claustro, finjan arrepentimiento $y$, aparentemente regeneradas, se casen a la primera oportunidad "con quien después no quieren hazer vida", con lo que el remedio se torna en perjuicio. Por otra parte, el miedo a ser recluídas impulsa a muchas de estas mujeres de vida disoluta a abandonar la ciudad y a vagar por campos y estancias "sin oyr misa, ny la palabra de Dios, que podía mober sus corazones para mudar su mal estado".

3) Respecto a las casadas que se hallan en proceso de separación, la dureza del recogimiento puede provocar en ellas efectos disuasorios e inducirlas a volver con sus maridos. Pero ha de tenerse en cuenta que en caso de que la demanda de divorcio fuese justa, la mujer no debería ser sometida a medida coercitiva alguna, con lo que al encerrarla se estaría cometiendo una grave injusticia, amén de propiciar la reanudación de una vida conyugal con frecuencia pecaminosa.

4) No ha de ponerse el acento de la honestidad femenina tan sólo en la forma de vestir, como se venía haciendo, pues muchas de las mujeres que eran confinadas por andar vestidas de indias sin serlo, no lo hacían por inmodestia, sino por pobreza, ya que el "traje de yndia" podía adquirirse por nueve o diez pesos, mientras que los vestidos de españolas superaban los doscientos, con lo que "si an de ganar estos trajes de la manera que ganan los bestidos de las yndias, será necesario hagan más ofensas a Dios y con más número de hombres".

5) Por último, la existencia de tales centros de reclusión da lugar a que los funcionarios sin escrúpulos abusen de su autoridad con las mujeres, "a las quales persuaden consientan con su volun- 
tad, y no consintiendo, que las prenderán y encerrarán en Santa Marta; y ellas, por no ser llevadas, hazen lo que quieren los dichos mynistros de justiçia, los quales llevan las que quieren y dexan las que les antoxan".

La argumentación de fray Bartolomé, desarrollada integramente en su respuesta a la quinta pregunta del interrogatorio, ${ }^{21}$ resulta en principio la más innovadora del conjunto, en la medida en que supone un rechazo a los centros de reclusión de mujeres y una condena de la coerción como medio de garantizar el respeto a la moral católica imperante. Sin embargo, algunos comentarios incluidos en ella, como el de "que si se an de recoxer todas las mugeres que tienen este trato desonesto, es menester de cinco partes dellas encerrar las quatro", nos inducen a matizar esta impresión y a preguntarnos hasta qué punto los alegatos de fray Bartolomé son la expresión de un auténtico deseo de reformación o simplemente están dictados por la hostilidad hacia don Luis, un prelado del que sus coetáneos afirmaban que "aunque lleva hábito agustino, su corazón es jesuita". ${ }^{22}$ En efecto, desde que López de Solís había ocupado la sede quiteña se había apoyado para su acción pastoral preferentemente en los padres de la Compañía. De ellos se hacía acompañar en sus visitas a la diócesis, a ellos encargó la dirección del seminario conciliar y por su envío a tierras ecuatorianas clama en las cartas dirigidas al rey, "por el mucho fruto que an hecho y hazen con su doctrina". ${ }^{23}$

Sería necesario conocer mejor la figura de fray Bartolomé y saber su procedencia para verificar si, además de la predilección demostrada por Solís hacia los jesuitas, pudieron existir otros motivos de animadversión entre el provincial agustino y el obispo. Particularmente interesante sería poder comprobar hasta qué punto el distanciamiento entre don Luis y la provincia agustiniana de San Miguel de Quito, puede ser un reflejo de la rivalidad entre los agustinos pe-

21 Ibídem.

22 Cit. López-Gay, J.: Agustinos en América a través de las cartas de los jesuitas. “Agustinos en América y Filipinas”, vol. I, pág. 453.

23 Ibídem, pág. 451. 
ruanos y los quiteños por el control del convento máximo de Quito, una rivalidad alimentada por la tardía consolidación de las divisiones provinciales, pues en veinticuatro años las demarcaciones de Perú y Quito se unieron tres veces y se separaron otras tantas: en 1579,1596 y 1603 , fecha de la secesión definitiva. ${ }^{24}$

No debe olvidarse por último la frecuencia con que en aquellas latitudes se producían choques entre el clero regular y la autoridad episcopal, a causa del control de las doctrinas y las intromisiones, más o menos justificadas, de los prelados en los asuntos internos de las órdenes. Los agustinos de Quito fueron ya desde el último cuarto del siglo XVI especialmente proclives a este tipo de enfrentamientos, baste recordar el habido entre fray Gabriel de Saona y el obispo de la Peña por la dirección del colegio de San Andrés tras la renuncia de los franciscanos. Esa tendencia se vería incrementada de forma constante en las décadas siguientes, en las que se multiplican las fricciones con la autoridad episcopal, la Audiencia y algunas órdenes religiosas, entre ellas la Compañía de Jesús, al tiempo que se agudiza la crisis de la provincia agustiniana de San Miguel. ${ }^{25}$

El testimonio del padre Onofre representa la otra cara de la moneda. Nacido en Chachapoyas hacia 1563-1564, en el seno de una acaudalada familia, fue educado en Lima por los jesuitas, ingresando muy joven en la Compañía. Trasladado al colegio de Quito en 1587, junto con los padres Juan de Anaya y Jerónimo de Castro, permaneció en él hasta su muerte, acaecida el 3 de noviembre de 1638. Su preocupación por el indio y su afán evangelizador, unido al dominio de las lenguas nativas, hicieron de él un excelente predicador y un incansable misionero. La labor evangelizadora del padre Onofre se extendió tanto por tierras del corregimiento quiteño, como por las de lo que sería el gobierno de Atacames o de Esmeraldas, el de Cara y el de Quixos. Su celo misional y la cari-

24 Calancha A. de la, y Torres, B.: Crónicas agustinianas del Penú, Madrid, 1972, vol.I, págs. 85-86 y Paniagua Pérez, J.: Los agustinos en la Audiencia de Quito. -Notas para su estudio- (1573-1650), "Agustinos en América y Filipinas", vol.I, págs. 263-264.

25 En el trabajo del profesor Paniagua Pérez sobre Los agustinos en la Audiencia de Quito..., puede hallarse una buena síntesis sobre todas estas tensiones. 
dad demostrada en la atención a los afectados por la terrible peste que desde finales de 1589 asoló toda la América meridional, le valieron el sobrenombre de "Apostol de Quito" y, sin duda, el afecto del obispo Solís, al que es posible que acompañara en la visita pastoral emprendida en $1596 .{ }^{26}$

El jesuita se declara estrechamente vinculado a la fundación del recogimiento, para el que en alguna ocasión ha pedido limosna por las calles de Quito, y decididamente favorable a su pervivencia, para la que considera vital dotarle de renta suficiente. Justifica su parecer en los benéficos resultados logrados, "pues hasta agora se puede dezir que se han remediado muchos pecados públicos con sólo el nonbre de la dicha casa de Santa Marta". Apoyándose en su propia experiencia, afirma que en los doce años que lleva en aquella ciudad y tierras circundantes, ha experimentado la dificultad de luchar contra la disolución de indias y mestizas en el vestir y en el vivir, la imposibilidad de acabar con "el mal vicio" de las casadas de solicitar divorcio sin causa justificada y la necesidad de un lugar donde se criasen y adoctrinasen tantas niñas huerfanas y pobres, para evitar que se perdiesen, por no poderse sustentar ni tomar estado. El recogimiento ha venido a ser remedio eficaz, "porque, desde que ansí se fundó acá, a bisto... que algunas que conosce que estavan en el dicho ávito de indias se pusieron y tornaron al ábito de españolas $y$ an perseberado en él hasta agora, y otras que eran yncasables se an casado... Lo qual tiene entendido fuera cosa ynposible, si no fuera por medio de la dicha casa de Santa Marta". Igualmente positivos considera el padre Onofre los logros en los procesos de separación, que "este testigo pudiera destos exemplos traer aquí muchos, porque an pasado por sus manos", y los que se esperan obtener en la educación de las doncellas allí recogidas. ${ }^{27}$

$\mathrm{Al}$ igual que el parecer de fray Bartolomé sobre la fundación parece estar mediatizado por las poco cordiales relaciones con el prelado quitense, también la defensa del jesuita denota, por su tono

26 López-Gay, Agustinos en América..., págs. 451-452, "Relación de Diego Rodríguez Docampo", págs. 48-49 y Velasco, J.: Historia del Reino de Quito, Caracas, 1981, págs. $327-328,370-372,376-379$ y $419-420$.

27 AGI, Quito, 76, fols. 792-796. 
exaltado, una cierta falta de objetividad motivada por la estrecha colaboración existente entre el obispo Solís y la Compañía.

Al margen de los juicios de valor vertidos por los ocho testigos entrevistados, de la información practicada por la Audiencia se desprende que, en 1600, el Recogimiento llevaba ya funcionando desde hacía más de cuatro años, bajo la dirección de una mujer de intachable vida y costumbres, doña Juana de Cáceres, a la que en alguna ocasión se alude como la fundadora. La casa que le servía de albergue estaba dotada de torno y capilla, con privilegio para oficiar misa y era, como la mayoría de las del casco central quiteño, de dos altos, pero tan estrecha que únicamente constaba de dos reducidas estancias por planta y "un patiezillo muy pequeño, que será de treynta o quarenta pies y no más, donde tienen toda la servidumbre de la dicha casa". ${ }^{28}$ A pesar de que en esta relación no se precisa la ubicación de Santa Marta, se sabe, por una reclamación formulada en 1703 por el capitán Yerovi Peña, que se hallaba situada en la colación de la catedral. ${ }^{29}$ Nada se especifica tampoco sobre el número de mujeres y niñas allí recogidas y aunque la mayoría de los testigos coinciden en afirmar que había muchas y de los tres tipos para los que se creó la institución -descarriadas, divorciantes y huérfanas-, es seguro que su número no pudo ser demasiado elevado, habida cuenta del reducido espacio con que contaban.

El recogimiento carecía de rentas e ingresos propios, de manera que dependía totalmente de la caridad para su supervivencia. Tanto el capellán como los confesores que atendían espiritualmente la casa, lo hacían de limosna por orden del obispo Solís, su principal valedor. Las necesidades materiales de las internas -comida, vestido, atención sanitaria - eran costeadas con los donativos episcopales, a los que se añadían algunas limosnas de particulares y la hacienda de doña Juana de Cáceres. Las carencias más perentorias de la fundación eran pues dos: un edificio mayor y mejor adaptado a sus funciones y una renta segura y suficiente. ${ }^{30}$

28 Ibídem, fol. 795.

29 AGI, Quito, 182, fol. 588.

30 AGI, Quito, 76, fols. 777-804. 


\section{La evolución de la casa de Santa Marta durante el siglo XVII}

En 1604 era propuesto para la diócesis quiteña el dominico fray Salvador de Ribera. ${ }^{31}$ Don Luis López de Solís, ascendido para la metropolitana de Charcas y propuesto después para la archidiócesis de Lima, moría en julio de 1606 en la capital del virreinato sin que ni sus peticiones ni las del Cabildo quiteño hubiesen obtenido de la hacienda real ningún apoyo económico para Santa Marta. ${ }^{32}$ Sin embargo, pese a que Felipe III, tan magnánimo por esos años con otras instituciones religiosas - la recolección dominica de Nuestra Señora de la Peña de Francia y el monasterio de la Concepción, por ejemplo- y con algunos nobles, como el marqués de Cea, al que concede en 1601 el disfrute por tres vidas de los indios que habían vacado en la provincia de Quito por muerte de don Beltrán de Castro, no otorgó ningún apoyo financiero al recogimiento quiteño, éste estaba ya a principios del siglo XVII plenamente consolidado, como demuestra su prolongada pervivencia. ${ }^{33}$

El nuevo prelado era el tercer hijo de doña Elvira de Avalos y don Nicolás de Ribera "el Viejo", expedicionario en la campaña de conquista de Pizarro y Almagro, y uno de los fundadores y primeros pobladores de la Ciudad de Los Reyes, del que debió de heredar el espíritu combativo y polémico que caracterizaría sus dos provincialatos y su mandato episcopal. Enfrentado con sus hermanos de Orden por las irregularidades cometidas por fray Reginaldo Gamero y fray Francisco García en el monasterio de Santa Catalina de Sena y con los agustinos, a quienes retiró las licencias ministeriales, tuvo también roces con el poder civil. ${ }^{34}$ Dejando a un lado las condenas formuladas contra el fiscal de la Audiencia don Blas de Torres Altamirano por su escandalosa vida privada, la mayor tensión entre fray Salvador y el Alto Trịbunal se produciría por

31 AGI, Quito, 1, 137.

32 AGI, Quito 17, s/f.

33 AGI, Indiferente General, 614 y Quito, 1, 95 y 96.

34 Vargas Ugarte, Historia de la Iglesia en el Perú..., págs. 259-261 y 340. Egaña, Historia de la Iglesia en la América Española..., págs. 438-441. 
ciertos problemas jurisdiccionales, entre los que se cuentan los planteados en 1611 en torno al recogimiento de Santa Marta.

El dominico, amparándose en su condición de patrón del mismo, protesta ante el Consejo de Indias por la costumbre recientemente introducida por la Audiencia y por el corregidor Sancho Díaz Zurbano, de confinar mujeres en Santa Marta sin contar con licencia episcopal, uso que "a llegado a tanto, que ynvían a sus alguaziles que entren en el dicho recogimiento y vean lo que en él ay, sin envargo que ésta es obra meramente espiritual y eclesiástica y que en la puerta y torno tiene fixada pena de excomunión el dicho obispo que ninguno entre en la clausura del dicho recogimiento". Se lamenta además fray Salvador de la pretensión de los jueces civiles de negarle el derecho que le asiste a mandar encerrar a las mujeres de vida escandalosa o de dar orden de deposito para las que se hallan en proceso de separación. "De manera - concluye la queja - que se han hecho tan dueños que del todo an escluydo al dicho obispo de lo que es propiamente suyo, quedándose con sólo el cuidado y cargo de sustentarlo y proveer de lo necesario". ${ }^{35}$

No fue necesario en esta ocasión esperar el arbitraje real para acallar las protestas, pues dos meses después de planteada la reclamación episcopal, el 16 de mayo de 1611 , el presidente de la Audiencia don Juan Fernández Recalde dictaba auto regulando la forma que debía observarse en la recepción de internas en el recogimiento. Con la nueva normativa se pretendía evitar desórdenes y obviar futuros conflictos de jurisdicción. Así lo debió de entender fray Salvador, ya que dos días más tarde daba su consentimiento oficial, ordenando que "se guarde y cumpla el dicho auto en todo y por todo como en el se contiene y declara". De acuerdo con lo en él dispuesto, se reservaba al obispo la facultad de depositar en Santa Marta las mujeres en proceso de divorcio o nulidad matrimonial; las acusadas de vida escandalosa podrían ser encerradas tanto por orden episcopal, como por orden del presidente y oidores de la Audiencia y deberían permanecer recluidas entre seis meses y un año, para que tuviesen tiempo suficiente de reflexionar y modificar sus hábitos de

35 AGI, Quito, 76, s/f. 
conducta; en cuanto al ingreso de las doncellas huérfanas que eran confiadas a la responsable de Santa Marta para ser formadas hasta la edad de tomar estado, éste debía ser acordado de forma conjunta por el obispo y el presidente de la Audiencia. La salida de las internas sólo podría ser decidida por la misma autoridad que las había encerrado en la casa. Con esta concordia se buscaba armonizar los derechos del obispo, al que le correspondía, de acuerdo con las capitulaciones de la fundación, el patronazgo de la institución, y la salvaguarda del patronato regio, cuya autoridad encamaba el presidente de la Audiencia según lo dispuesto por las cédulas de 23 de septiembre de 1563,3 de noviembre de 1567 y 11 de septiembre de $1569 .{ }^{36}$

Don Juan Fernández Recalde expresaba además en el auto de concordia la preocupación que le causaba el ver la casa de Santa Marta sin dirección, por haberla abandonado Juana Gómez, "persona que la tenía a su cargo", y rogaba al obispo Ribera se apresurase a señalar "una mujer de toda virtud y confianza, qual combiene para la dicha casa". De este modo quedaba también planteada y fijada la forma que debía observarse en el nombramiento de la responsable del recogimiento, cuya designación quedaba a cargo del prelado de la diócesis, reservándose la confirmación, el presidente del Alto Tribunal. ${ }^{37}$

No debía de ser tarea fácil hallar quien asumiese la responsabilidad de Santa Marta y no tanto porque faltasen candidatas de edad adecuada y virtud probada, como por las estrecheces que habían de pasarse en la dicha casa. Tal es, al menos, lo que se infiere del testimonio de María Ramírez, que a los pocos meses de su nombramiento se dirigía al presidente de la Audiencia solicitando se tuviese en cuenta al Recogimiento en el reparto de las limosnas de la cárcel, por no tener con qué sustentar a las personas allí depositadas, entre las que se contaban seis huérfanas, y hallarse todas a pique de morir de hambre. ${ }^{38}$

36 AGI, Quito, 182, fols. 590v-591 y Recopilación de las Leyes de Indias (Madrid, 1973, T. I, pág.13), Lib.I, Tit.VI, ley 26.

37 AGI, Quito, 182, fol. 590v.

38 Ibídem, fols. 591 v-592r. 
La gravedad de las dificultades económicas de Santa Marta y las insistentes peticiones de auxilio de su directora llevaron al presidente don Antonio de Morga a ordenar en 1617 una exhaustiva información sobre la situación en que se hallaba el Recogimiento. El escribano Diego de Valencia León fue el encargado de elaborarla, tomando como base el testimonio prestado por la propia María Ramírez. De acuerdo con sus declaraciones, existían en ese momento en la casa diecinueve internas: tres de ellas eran niñas mestizas de diez a doce años de edad; ocho eran mujeres casadas, la mayoría indias y mestizas, casi todas inmersas en procesos de separación; el resto eran doncellas casaderas que se preparaban para tomar estado. Una buena parte de ellas había llegado al recogimiento sin tener en cuenta la normativa fijada por la concordia de 1611: tres habían sido acogidas por María Ramírez para que la ayudaran en el servicio de la casa, al tiempo que aprendían buenas costumbres; tres de las jovenes casaderas y una de las niñas estaban depositadas allí por indicación del padre Onofre Esteban; y otra de las doncellas solteras, una india llamada Francisca, se hallaba acogida por deseo de la esposa del fiscal Melchor Suárez de Poago. ${ }^{39}$

La falta de control en la recepción de mujeres había agudizado las carencias del recogimiento. Los cuatro cuartos eran a todas luces insuficientes para las residentes, con lo que los problemas de convivencia y salubridad eran una constante amenaza. Igualmente escasos eran los recursos económicos con los que contaba Santa Marta para su manutención. Ni Felipe III, ni los sucesores de fray Luis en la diócesis - fray Salvador de Ribera y don Hernando Arias de Ugarte - habían concedido dotación alguna para esta obra pía, con lo que la única variedad en su siempre precaria economía consistía en cien pesos de plata de renta anual, cuya procedencia no se especifica, aunque bien pudieran ser un legado testamentario de doña Juana de Cáceres. De esa renta había de descontarse los veintiseis pesos que se pagaban a Francisca Baras por atender la puerta y el torno, y los catorce correspondientes al sacristán; con los sesenta

39 AGI, Quito, 182, fols. 592r-593. 
pesos restantes, a los que habría que añadir algunas limosnas de particulares - nunca demasiado abundantes al decir de María Ramírez- debía atenderse al gasto de vino y cera de la capilla y a todas las demás necesidades de la casa y de las internas, ya que sólo en contados casos éstas eran mantenidas por sus padres, maridos o deudos. Esta penuria financiera, prácticamente crónica, favorecería la temprana introducción de algunos abusos por parte de las rectoras de la casa, como el denunciado por Gaspar Gómez, procurador de pobres, ante el presidente Morga en 1618. Tras insistir en las muchas mujeres que se hallaban encerradas en Santa Marta sin haber mediado conocimiento de la Audiencia ni auxilio real para su reclusión, el procurador acusaba a María Ramírez de obligar a las internas a trabajar sin descanso "en labores y otros ministerios" para su propio provecho y sin paga alguna, así como de impedirlas la comunicación con sus familiares al no dejarlas acudir al torno ni siquiera para recibir alimentos. ${ }^{40}$

Es difícil precisar la veracidad de tales acusaciones. Desde luego no era inusual que las mujeres acogidas a este tipo de instituciones tuviesen que trabajar para subvenir a su manutención y tampoco que las rectoras encargadas de su cuidado se extralimitasen en sus funciones, como lo demuestra el ejemplo del recogimiento mexicano de Jesús de la Penitencia. ${ }^{41}$ Por otra parte, es evidente que la información practicada por el escribano Diego de Valencia y la denuncia del procurador de pobres tuvieron la credibilidad suficiente para que don Antonio de Morga dictase un nuevo auto el 12 de mayo de 1618 sobre el orden que debía observarse en la recepción de internas en Santa Marta. El presidente se limitó a recordar la concordia aprobada en 1611, sin introducir innovación alguna ni menoscabar la autoridad del obispo Alonso de Santillán, que de acuerdo con su talante habituạl, se limitó a acatarlo pacientemente. ${ }^{42}$

El silencio documental sobre la evolución del recogimiento durante el resto del siglo XVII es casi absoluto. Las noticias localiza-

40 Ibídem, fols. 593v-594r.

41 Muriel, Los recogimientos de mujeres, págs. 47-56.

42 AGI, Quito, 182, fols. 594-595r. 
das se reducen a la mención recogida por el comisario general de la Orden carmelitana Vázquez de Espinosa, que en su Compendio y descripción de las Indias Occidentales se limita a constatar su existencia, y a las contenidas en la relación del estado eclesiástico elaborada por Rodríguez Docampo en 1650, siendo obispo don Agustín de Ugarte y Saravia. De este último informe parece inferirse que Santa Marta había perdido por estas fechas su condición de centro formativo de doncellas, quedando esencialmente como institución de acogida para las mujeres en proceso de divorcio o nulidad matrimonial. Sus rentas debían de seguir siendo escasas, y a sus cargas se añadía ahora la manutención del capellán, en ese momento el clérigo Juan Bautista Zurita. ${ }^{43}$

La evolución de la economía quiteña, en franco deterioro desde 1630 por la paulatina supeditación del obraje a la hacienda, las erupciones volcánicas del Pichincha (1660-1661) y las epidemias y seismos de los años centrales del siglo, ${ }^{44}$ agudizaron seguramente las carencias que Santa Marta venía sufriendo desde su fundación. Aunque tanto Felipe III como Felipe IV no dejaron de recomendar en las instrucciones de los virreyes que se potenciasen los recogimientos y se procurase persuadir a las personas que pretendían fundar conventos para que destinasen sus bienes a centros de acogida para huérfanos y doncellas, seguían siendo las instituciones monásticas las que atraían las donaciones y el interés de los obispos y particulares. ${ }^{45}$ En efecto, el Carmen de San José, fundación promovida y dotada por don Agustín de Ugarte y aprobada por cédula real de 2 de abril de 1651, y la reedificación del santuario de la Virgen de Guápulo, junto con el fallido intento de establecer en él un centro

43 Vázquez de Espinosa, A.: Compendio y descripción de las Indias Occidentales, 2." parte, Madrid, 1992, pág. 509 y "Relación de Diego Rodríguez Docampo", págs. 48-49.

44 Para una aproximación a la evolución económica de Quito resulta imprescindible el trabajo de Miño Grijalva, M.: La economía de la Real Audiencia de Quito (siglos XVII y $X V I I I)$, en "La economía colonial. Relaciones socio-económicas de la Real Audiencia de Quito", Quito, 1984, págs. 14-85. En cuanto a la incidencia de las catastrofes naturales, véase Velasco, Historia del Reino de Quito, págs. 322-330.

45 Recopilación de Leyes de los Reinos de Indias (T. 1, pág. 13), Lib. 1, Tit. 3, ley 19. Herráez, J.: Beneficencia de España en Indias, Sevilla, 1949, pág. 74. 
de oratorianos de San Felipe de Neri, parecen acaparar las ya comprometidas fuerzas de la sociedad quiteña. ${ }^{46}$

Relegado y siempre amenazado por la extrema necesidad a que le condenan sus exiguas rentas, el recogimiento de Santa Marta sobreviviría, pero sin poder evitar ni las frecuentes injerencias de las autoridades civiles, provocadas —en opinión del marqués de Varinas- ${ }^{47}$ por una cada vez más abusiva interpretación del patronato real, ni tampoco la sustancial alteración de su carácter fundacional.

\section{La transformación de Santa Marta en cárcel privada}

De acuerdo con las tesis del profesor Miño Grijalva, a partir de 1680 se detecta en el área quiteña una aparente revitalización del sector obrajero, que podría ser indicativa de una cierta reactivación económica. Ese ambiente de relativo optimismo expansivo iba a permitir al Recogimiento abandonar a principios del siglo XVIII su primitivo solar. Favorecería asimismo la mudanza el apoyo del presidente Mateo de la Mata y el estado ruinoso del inmueble que en su día donara Alonso de Moreta. El doctor de la Mata había llegado a Quito en 1691 procedente de la Audiencia limeña en calidad de visitador, pero habiendo muerto ya a su llegada el presidente de Munive, fue designado para sucederle. Su estancia en la Audiencia quiteña se prolongaría casi tres lustros, durante los cuales, además de vivir el cambio dinástico, le tocó afrontar las consecuencias de la mortífera epidemia de 1693 y del no menos destructor terremoto de $1698 .{ }^{48}$

En medio del clima de exaltación piadosa que este tipo de circunstancias luctuosas solía generar, el presidente, actuando de acuer-

46 Paniagua Pérez, J.: Los oratonianos en la Audiencia de Quito, "Revista del Archivo Nacional Histórico de Ecuador. Quito", (en prensa) y Vargas, J. M.: La Iglesia y el Patrimonio cultural ecuatoriano, Quito, 1982, págs. 53-54.

47 Fernández Villalobos, G.: Estado eclesiástico, político y militar de la América, Madrid, 1990, págs. 537-572.

48 Szaszdi Nagy, A.: El distrito o reino de Quito, "América en el siglo XVII", T. IX-2 de la Historia General de España y América, Madrid, 1984, pág. 308. 
do con el prelado Sancho Pardo de Andrade, acometió el traslado de las recogidas a una nueva casa más amplia y mejor adaptada a sus fines, a la que tenía previsto anexar la obra pía de los expósitos. La nueva construcción fue financiada con el producto de una derrama impuesta a los vecinos por el presidente De la Mata y las limosnas aportadas por el obispo Andrade, los capitulares catedralicios y el Cabildo de la ciudad, más los mil pesos que, conforme a la tasación realizada por el maestro alarife Jaime Ortiz, pagó el capitán Martín de Yerobi Peña por el viejo inmueble. ${ }^{49}$ De acuerdo con el plano levantado en 1751 por la misión geodésica francesa dirigida por La Condamine, el nuevo recogimiento se hallaba a dos manzanas de la Plaza Mayor, muy cerca del Carmen de Latacunga. ${ }^{50}$

El traslado de las recogidas a su nueva casa se produjo el 13 de agosto de 1703, cuando todavía no se hallaban totalmente concluidas las obras. No se ha localizado descripción alguna de las dependencias, pero lo más probable es que su estructura se asemejara en lo esencial a la de todas las fundaciones conventuales femeninas. La mudanza no debió de suponer una mejora sustancial, a tenor de lo afirmado en la consulta elevada en 1722 a Felipe V, en la que se asegura que el recogimiento, "en tocante a lo material de la casa, es vien estrecho, desacomodado y poco seguro". ${ }^{51}$ Primero la sustitución de Don Mateo de la Mata por el oidor limeño don Francisco López Dicastillo, luego el nombramiento del obispo Diego Ladrón de Guevara como virrey, que supondría el alejamiento de su diócesis desde 1710, y después el cambio de coyuntura producido en torno a ese mismo año, que acaba con las esperanzas de revitalización de las fuerzas productivas e inicia un prolongado período de estancamiento y ruralización económica, debieron de frustrar los planes originales de engrandecimiento de Santa Marta hasta tal punto, que

49 AGI, Quito, 182, fols. 527r, 588-590 y 595-599.

50 Véase plano adjunto tomado de Hardoy, J.E., y Dos Santos, M.R.: Centro Histórico de Quito. Preservación y Desarrollo, Quito, 1984. En este mismo lugar lo ubica T. López, con la denominación de "Santa Marta. Carcel de mujeres", en su plano de Quito de 1786. (Sánchez Zurro, D. (ed.): Castilla y León en América. Cartografia Histórica, Valladolid, 1991).

51 AGI, Quito, 182, fol. 527. 


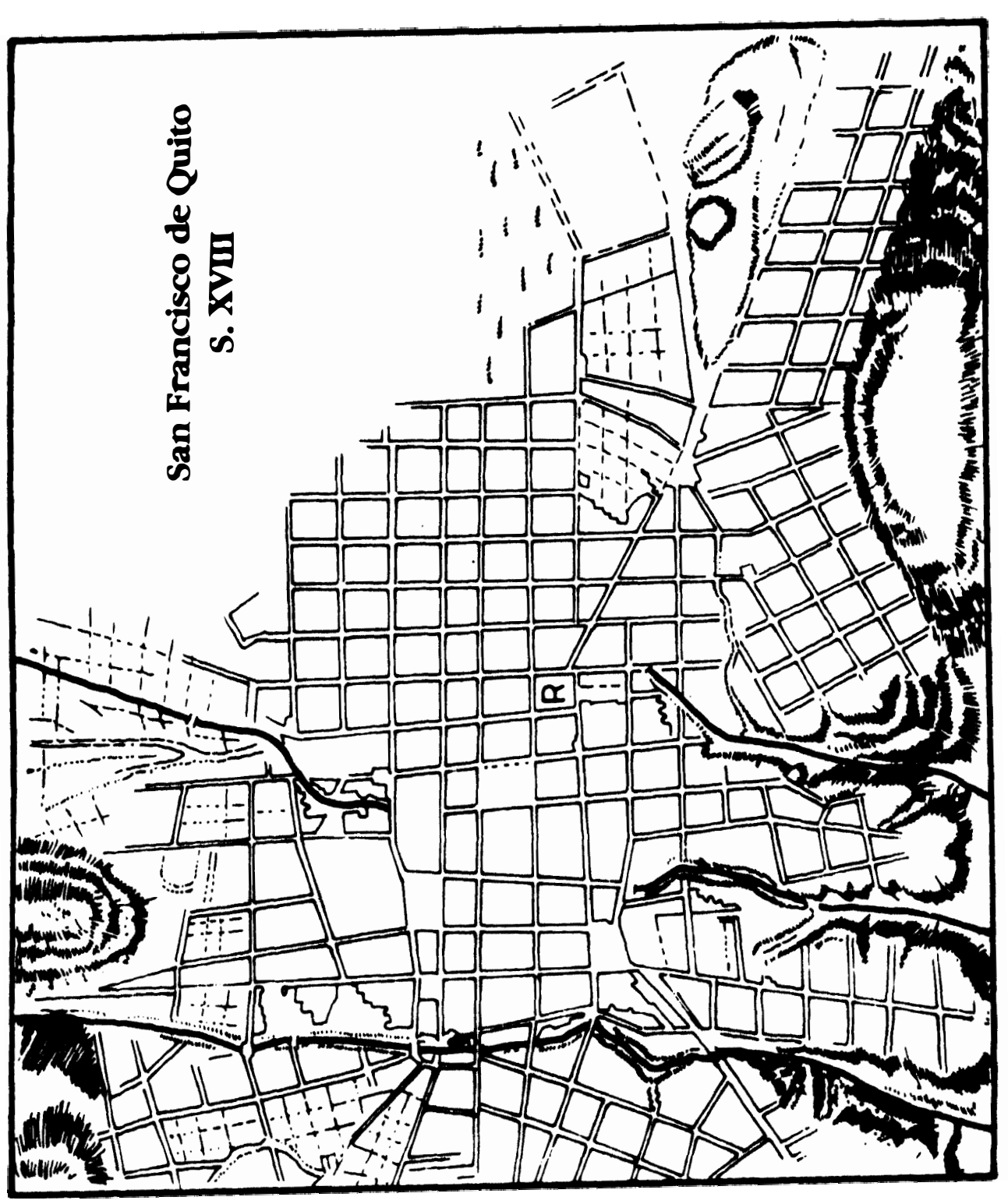

三 
la variación del emplazamiento fue prácticamente la única novedad reseñable. ${ }^{52}$

La situación económica de la institución, lejos de sanearse, tendió a empeorar: los cien pesos de renta anual se habían perdido; no había con qué pagar al capellán, que tenía que decir las misas de limosna; el cargo de rectora se había convertido en un medio de vida para la mujer que lo ostentaba y como para su manutención sólo tenía el carcelaje, era habitual que, para aumentar sus ingresos, obligara a las recogidas a hilar, coser y lavar, e incluso que admitiera sobornos por darles permisos nocturnos o dejar entrar en la casa a sus galanes; las internas ya no son mantenidas por el centro, que ni siquiera les proporciona cama, y tienen que vivir de lo que "las traen de fuera sus parientes, y si no se lo traen perescen". ${ }^{53}$

La decadencia económica del Recogimiento corre pareja con su declive moral: la rectora ha dejado de ser la dama de buenas costumbres que entrega generosa y voluntariamente su vida en pro de la educación y asistencia de las recogidas, para convertirse en una carcelera con frecuencia dura y artera; ya no alberga la casa, como en sus orígenes, mujeres arrepentidas deseosas de llevar una vida honesta, ni doncellas en formación aguardando la hora de tomar estado, tan sólo recogidas forzosas que han sido llevadas a él para hacerlas desistir de los procesos de divorcio o nulidad matrimonial entablados, o como correctivo por haber sido sorprendidas en flagrante delito de adulterio o prostitución.

Así pues Santa Marta, en sus poco más de cien años de existencia, ha perdido totalmente su carisma fundacional, dejando de ser un centro benéfico-asistencial de acogida para huérfanas y mujeres arrepentidas, especialmente mestizas, para convertirse en un centro de reclusión y castigo. Desde luego, la transformacion de los recogimientos de mujeres en centros de reclusión no debió de ser un fenómeno privativo de la Audiencia quiteña, ni del virreinato del Perú, sino común a todo el ámbito hispanoamericano, según se desprende del estudio sobre los recogimientos novohispanos de Josefina

52 Miño Grijalva, La economía de la Real Audiencia de Quito..., págs. 17-19.

53 AGI, Quito, 182, fols. 527-528. 
Muriel. Sin embargo, los escasos trabajos existentes sobre este tipo de instituciones imposibilitan de momento la verificación de esta hipótesis.

Entre los factores que pudieron contribuir a la metamorfosis de los recogimientos, y en particular del de Santa Marta, cabría destacar el creciente rechazo de chapetones y criollos hacia los mestizos, directamente proporcional al fuerte crecimiento biológico de éstos y a la amenaza que su aumento podía comportar para la conservación de los privilegios de la élite blanca. Durante el siglo XVI y hasta mediados de la centuria siguiente los mestizos - parafraseando al profesor Mijares - habían sido considerados como "gente estimable" y como tal digna de gozar de los mismos derechos y educación que sus progenitores hispanos, y a esa consideración respondía la fundación del obispo Solís. Sin embargo, desde la mitad del XVII su condición legal y social sufre un creciente deterioro. Cada vez son menos los mestizos legítimos o legitimados y cada vez es mayor su marginación, por lo que las instituciones orientadas a su formación y asistencia pierden sentido y desaparecen o se transforman, como en el caso de los recogimientos femeninos, en cárceles sui generis. ${ }^{54}$

Si el rechazo al mestizo es una manifestación de la evolución de la sociedad colonial, cada vez más jerarquizada y estratificada, no lo es menos el fatalismo reinante sobre la condición moral del indígena. Aunque este indio siempre había gozado de protección legal, su integración estaba lejos de ser total, sobre todo si por tal se entiende la asimilación y aceptación de la ideología y las pautas vitales de la élite blanca. La resistencia del indio ante los patrones de conducta dominantes lleva a la convicción de su inferioridad moral y de la necesidad de contar con medios de represión para castigar sus pécados-delitos. Este sentir, común a las autoridades civiles y eclesiásticas quiteñas, queda perfectamente reflejado en juicios como

54 Respecto a la evolución social, pueden ser síntesis válidas tanto la elaborada por L. Mijares sobre la sociedad hispanoamericana del XVII para la Historia General de España y América (T. IX-1, Madrid, 1985, págs. 169-221), como la realizada por M." Angeles Eugenio sobre la sociedad dieciochesca para el T. XI-1 de la misma Historia (Madrid, 1983, págs. 243-266), e igualmente la de Navarro García, L.: Hispanoamérica en el siglo XVIII, Sevilla, 1975, especialmente págs. 5-12. 
el contenido en la consulta elevada por el obispo don Francisco Romero a Felipe $V$ en 1722 , en la que se afirma que indios y mestizos, "por su vaja y vil naturaleza, son ynclinados a la sensualidad y falta de fee". ${ }^{55}$

Desde luego que no fueron las diferencias étnicas los únicos criterios de estratificación social y que no pueden menospreciarse los condicionantes económicos, entre otras razones porque la posición económica fue esencial para definir el status en la sociedad colonial dieciochesca, pero se ha puesto el acento en ellos porque el acceso a las fuentes de riqueza estuvo en buena medida determinado por condicionantes raciales, de manera que, en líneas generales, hablar de "gente baja" equivale a hablar de mestizos o indios. En este sentido, aunque Santa Marta no es un centro de reclusión exclusivo para indias y mestizas, sí parecen ser éstas las que constituyen el grueso de su población.

Por último, justifica también la existencia de este tipo de centros de represión la propia concepción de la mujer y la moral formal imperante en la sociedad colonial. Aunque, de acuerdo con el testimonio del promotor fiscal del obispado, eran igualmente merecedores de castigo los adulterios y amancebamientos de ambos sexos y de hecho a los varones hallados culpables se les recluía en un aposento de los palacios episcopales hasta haber logrado su arrepentimiento y confesión, se insiste siempre en que el encierro de la mujer ha de ser especialmente riguroso "por naturaleza del sexo, que no permite aquella libertad que quisieran por el peligro a que son inclinadas" y porque esta "variedad la introduxo la diversidad de los sexos, tan sin peligro en los hombres y tan peligroso en las mugeres". Por otra parte, mientras las casas de mancebía fueron siempre toleradas como un mal necesario, se persiguió y condenó a las mujeres que ejercían la prostitución fuera de ellas, por entenderse que su proceder era más escandaloso y nocivo para la sociedad. En cuanto a los casos de divorcio o nulidad, siempre late en ellos la idea de la culpabilidad femenina, y por ello, lo que había comenzado siendo un depósito para garantizar el que la mujer pudiera se-

55 A.G.I, Quito, 182, fol. 527v. 
guir libremente su causa matrimonial, se convierte con el tiempo en un medio de represión para lograr que retire su demanda y se salvaguarde la autoridad del marido, al que en todo momento se le reconoce "dominio sobre el cuerpo y persona de la muger", y la indisolubilidad del vínculo conyugal. ${ }^{56}$

Convertida Santa Marta en una institución de reclusión forzosa, no tardarán en surgir en torno a ella conflictos jurisdiccionales. Las tensiones entre la justicia civil y la eclesiástica por problemas competenciales no eran nuevos, como lo demuestran las constituciones de 1611 y 1618. Los Austria, aprovechando al máximo la concesión efectuada a los Reyes Católicos por Alejandro VI en 1493 y la obtenida por don Fernando del papa Julio II en 1507, habían ido aumentando el control sobre la Iglesia indiana, amparados en el patronato regio primero y en las tesis vicariales, ardientemente defendidas por Solórzano, Araciel y Frasso, a partir del siglo XVII. La entronización de la dinastía borbónica no supuso sino la continuación e intensificación de esa política, reforzada por el desarrollo de las doctrinas regalistas. El reinado de Felipe V no comportó, por tanto, un cambio sustancial de la política religiosa en el ámbito americano, pero las difíciles relaciones entre el Papado y la Corona española no hay duda de que contribuyeron a propiciar no sólo un aumento de conflictos competenciales, sino también la creciente subordinación de las autoridades religiosas al poder temporal. ${ }^{57}$

El recogimiento de Santa Marta será uno de los centros sobre el que la creciente tensión entre el poder civil y el eclesiástico dejará su impronta durante el primer cuarto del siglo XVIII. El primero de los conflictos surgirá en 1721 , a raíz de la denuncia formulada ante el Cabildo quiteño por el alguacil mayor de la ciudad, a causa de lo que considera extralimitaciones de los jueces y ministros eclesiásticos, que prendían y ejecutaban en los bienes de los detenidos sin el preceptivo auxilio real, contraviniendo lo dis-

56 Las citas textuales pueden contrastarse en AGI, Quito, 182, fols. 553v-555r; sobre el tratamiento del sacramento del matrimonio en los concilios celebrados en la capital del virreinato remitimos a Tineo, P.: Concilios limenses y evangelización americana, Pamplona, 1990, págs. 196-200 y 422-425.

57 Hera, A. de la: "El Patronato y el Vicariato regio en Indias" y "El Regalismo indiano", Historia de la Iglesia en Hispanoamérica y Filipinas, Madrid, 1992, págs. 63-97. 
puesto en la ley XII, título X, del libro primero de la Recopilación de las Leyes de Indias. La acusación se justificaba tanto por la defensa de la jurisdicción real, particularmente encomendada en la ley I del mismo título y libro de la Recopilación, como por el perjuicio económico que recibía el alguacil al verse privado de los derechos de las ejecuciones, principal gaje de este patrimonializado oficio. ${ }^{58}$ Poco tiempo después el corregidor don Diego de Zárate, sensibilizado quizás por estas quejas, acudió a Santa Marta haciendo soltar a quince de las mujeres depositadas en el recogimiento por haber sido recluidas sin el preceptivo "auxilio real". Protestaron por su actuación las autoridades eclesiásticas, argumentando ser Santa Marta una fundación episcopal y corresponder al obispo la intervención en todas las causas de divorcio, nulidad, adulterio, amancebamiento y pública prostitución. Medió el presidente de la Audiencia don Santiago de Larraín, reconociendo salomónicamente el derecho del mitrado a ordenar depósitos de mujeres en causas matrimoniales y la necesidad de auxilio real en los casos de mixto fuero - adulterios y amancebamientos públicos-, y otorgando éste con carácter general para todas las reclusiones ordenadas por la autoridad eclesiástica, en atención a que éstas se hacían por "evitar pecados y morigerar escandalosas costumbres, que es el fin a que an de aspirar ambos brazos secular y eclesiástico". ${ }^{59}$

Dos años más tarde vuelven a suscitarse tensiones entre ambas autoridades, encarnadas en ese momento en don Jerónimo de Abel de Beas, nombrado corregidor el 6 de octubre de 1721, y el obispo don Francisco Romero. El conflicto se suscitaría básicamente en torno a dos casos: el de María Suárez de Figueroa, que había puesto demanda de divorcio contra su esposo, el sombrerero Eugenio Alvarez, y el de la india Tomasa Curimalqui, sobre la que pesaba una múltiple acusación de adulterio.

58 AGI, Quito, 182, fols. 544v-545. De la patrimonialización del oficio de alguacil y su valor se hace eco F. López de Caravantes en su Noticia general del Perú, II, Madrid, 1986, pág. 195.

59 La información documental corresponde a AGI, Quito, 182, fols. 528v-529, 538, 553 y 585v. Las referencias legales pueden contrastarse en Recopilación de Leyes de los Reinos de Indias, T. 1, págs. 46 y 48. 
La primera, María Suárez, había iniciado los trámites de separación en junio de 1723 , alegando incumplimiento de las obligaciones conyugales y constantes malos tratos por parte de su marido y solicitando que se le permitiese refugiarse durante el tiempo que durase la causa en una casa de reconocida honra, la de doña Leonor Guerrero y el capitán don Gregorio Suárez. A los pocos días Eugenio Alvarez denunció a su mujer por haber abandonado la casa de doña Leonor y haberse refugiado sin causa alguna en el monasterio de Santa Catalina, y solicitó ante las autoridades eclesiásticas que se la exhortase a la reconciliación o se la encerrase en la casa de Santa Marta. De acuerdo con la primacía reconocida a la autoridad marital, el promotor fiscal del obispado, don Martín Sánchez Grande, fracasados los intentos de arreglo matrimonial, procedió con licencia del provincial de Santo Domingo fray Vicente Vallejo y de la abadesa de Santa Catalina, sor Baltasara de San Juan, a trasladarla al recogimiento, donde quedó depositada desde el 6 de agosto bajo la custodia de Juana de Morales, rectora de la institución. Diez días más tarde, lo que hasta entonces no había sido más que uno de tantos casos de divorcio, se convertiría en el precipitante de un grave conflicto jurisdiccional, al personarse en Santa Marta el corregidor Abel de Beas, liberar a María Suárez, argumentando que ni el prelado, ni ninguno de sus ministros tenía facultad para ordenar reclusión alguna, puesto que ésta era privativa de las justicias reales, y conminar a la rectora a que, bajo multa de veinte pesos, no admitiese más depositos en la casa que los ordenados por él. ${ }^{60}$

El 17 de agosto la autoridad episcopal respondía excomulgando al corregidor, al que consideraba incurso en la censura prevista en la bula de la Santa Cena para todos los ministros que intentasen entorpecer o menoscabar la jurisdicción eclesiástica, ${ }^{61}$ y ordenándo-

60 AGI, Quito, 182, fols. $532-535$ y $536 \mathrm{v}-540$.

61 La bula In Coena Domini fue durante toda la época colonial motivo de constante fricción entre el poder temporal y el eclesial. Para comprender los recelos que siempre despertó en los monarcas españoles basta revisar la real cédula de 27 de noviembre de 1768, en la que se recogen los recursos y prohibiciones planteados desde su promulgación en 1551. Ayala, M. J. de: Diccionario de Gobierno y Legislación de Indias, T. II, Madrid, 1988, páginas 218-220. 
le que devolviese al recogimiento a María Suárez bajo pena de doscientos pesos de multa. Durante las semanas siguientes se cruzaron continuos memoriales, autos y notificaciones en defensa de los respectivos derechos de ambas justicias. En síntesis, el provisor y el promotor fiscal del obispado acusaban al corregidor de haberse entrometido en causas que sólo competían al ordinario eclesiástico, como eran las de nulidad y divorcio, y confundir el depósito, que no requería sentencia firme alguna, con la prisión, que ya presuponía condena. Don Jerónimo Abel de Beas defendía su proceder asegurando no haber hecho más que cumplir con el juramento de su toma de posesión, que le obligaba a no permitir que se prendiese a personas legas sin mediar el auxilio real, e insistiendo en que el término "depósito" no era sino un eufemismo para encubrir la prisión, puesto que como tal se debía considerar a todo encierro que, como el de María Suárez, se efectuase en contra de la voluntad de la persona recluida. ${ }^{62}$

La Audiencia, temiendo tal vez un perjudicial fortalecimiento de la autoridad del corregidor, optó por inclinarse a favor de los argumentos eclesiásticos y ordenó que María Suárez fuese restituida de inmediato al Recogimiento. Su mandato fue cumplido y la mujer quedaría encerrada en Santa Marta hasta que, tras haberse apartado de la querella de divorcio, fue entregada a su marido el 1 de septiembre. Sin embargo, las diferencias entre el corregidor y el obispo no desaparecieron. Don Jerónimo Abel de Beas, considerando que el conflicto jurisdiccional se hallaba sin resolver, puesto que no se había sustanciado su apelación ante el arzobispo y virrey del Perú fray Diego Morcillo Rubio, se negaba a formular el juramento de no intromisión en la jurisdicción eclesiástica que se le exigía y a abonar la multa impuesta, alegando además estar prohibido imponer ni censuras por causas leves ni penas pecuniarias a los seglares. ${ }^{63} \mathrm{El}$ obispo Romero se mantuvo firme en la exigencia de la caución juratoria, pero transigió con el levantamiento de la multa,

62 AGI, Quito, 182, fols. 541-544 y 546v-547r.

63 Lib. I, tit. VII, ley 47 de la Recopilación de Leyes de los Reinos de Indias, T. 1, pág. 39 y AGI, Quito, 182, fols. 536, 547v-563 y 566-568. 
aunque dejando a salvo el derecho eclesiástico a imponer censuras y multas, amparado en el Concilio de Trento y en la bula In Coena Domini y avalado por antecedentes como el del arzobispo de Lima don Antonio de Soloaga, que en 1717 había multado y excomulgado a los alcaldes ordinarios de la ciudad por haber sacado a un reo de asesinato, don Juan Manuel Ballestero, de la iglesia de la Recolección franciscana, sentencia que fue confirmada por Felipe $\mathrm{V}$ en 1720. El corregidor Abel de Beas, apremiado por la necesidad de concluir la recaudación de los tributos todavía pendiente, hubo de prestar al fin el juramento requerido para obtener la absolución. ${ }^{64}$

No se habían acallado aún los ecos de este conflicto, cuando surgió un nuevo enfrentamiento por el castigo infringido por orden de don Gregorio Sepúlveda, lugarteniente del promotor fiscal, a una mujer llamada Tomasa Rodríguez. Según el escrito de denuncia presentado ante la Audiencia el 29 de octubre de 1723, el ministro eclesiástico, por vengarse de la citada Tomasa, la había hecho recluir en Santa Marta, mandando cortarle el cabello y azotarla, todo ello sin que mediara auto ni auxilio real. Los oidores Simón de Rivera, Pedro Martínez y Manuel Rubio dictaron de inmediato auto conminando a las justicias eclesiásticas a que solicitaran el preceptivo auxilio, ordenando la liberación de Tomasa y solicitando la intervención del prelado para castigar a Gregorio de Sepúlveda. El 9 de noviembre, tras la ratificación del auto mediante provisión real y la notificación oficial de la sentencia, Don Francisco Romero ordenó abrir una minuciosa investigación sobre el caso. El informe elaborado por el promotor fiscal del obispado demostró que la que se hacía apellidar Rodríguez era en realidad una india de apellido Curimalqui, que se hallaba casada con Cristóbal Tituana, también indio, con el que hacía tiempo que se negaba a mantener vida marital. Los acusadores testimonios de su esposo, de varías indias cuyos maridos habían estado amancebados con la citada Tomasa y de Esteban Márquez, coadjutor de la Iglesia Mayor, pusieron de manifiesto su es-

64 Las referencias documentales siguen perteneciendo a AGI, Quito, 182, fols. 558v559r y 567-571. El caso del arzobispo Soloaga puede contrastarse en A. de Egaña, Historia de la Iglesia en la América Española, pág. 815. 
candalosa vida y lo merecido del castigo a que se le había condenado, por reincidente e incorregible, con pleno consentimiento de su conyuge. Quedó comprobado además que el recurso había sido presentado por el capitán don Jacinto González, engañado por las falsas razones de su mayordomo José de los Reyes, último de los amantes de la india. En consecuencia, se exculpó a don Gregorio de Sepúlveda; se protestó por la actuación de la Audiencia, que no debía de haber admitido la queja por ser competencia del protector de indios; y se volvió a apelar al derecho que asistía al obispo y sus ministros a depositar mujeres en el Recogimiento sin necesidad de acudir al auxilio real, como pretendían las justicias civiles. ${ }^{65}$

Los argumentos esgrimidos son esencialmente los barajados en los casos anteriores:

1) El auxilio general concedido por los presidentes Mateo de la Mata y Santiago de Larraín, que los exime de cualquier otra formalidad.

2) La imposibilidad práctica de recurrir a dicho auxilio tanto por la cantidad de casos que se producen, como por ser las más de las personas implicadas en ellas demasiado pobres para seguir causas jurídicas.

3) El carácter de jueces ordinarios en todas las causas de indios, reconocido a todos los jueces eclesiásticos y curas doctrineros por el III Concilio Limense, las constituciones sinodales de la diócesis, el Itinerario para párrocos de Indias de don Alonso Peña y hasta por La política indiana de Solórzano.

La Audiencia, con el presidente Larraín al frente, respondió a la reclamación episcopal con el auto dictado el 7 de abril de 1724, por el que se determinaba: primero, que en caso de que el instituto de Santa Marta recuperase su antigua función de colegio de doncellas, la admisión de éstas debería corresponder al obispo y al presidente de la Audiencia de forma conjunta; segundo, de seguir utilizándose como centro de reclusión, correspondería al prelado el

65 lbídem, fols. 57 lv-587 y 600-605r. 
depósito y soltura en los casos de divorcio, por ser casos de su entera competencia, no así en las causas de mujeres de mal vivir, que por su carácter mixto requerían el auxilio de las justicias reales. ${ }^{66}$

A pesar de que en esencia se repetía la concordia de 1618, la resolución no satisfizo al obispo quiteño, que decidió apelar al dictamen real. No tenemos constancia del fallo regio, aunque se puede intuir del contrario informe emitido por el fiscal el 26 de septiembre de 1726, en el cual se recomendaba mandar observar la resolución de la Audiencia, así por su ponderación, como porque cualquier concesión que se hiciese a las justicias eclesiásticas iría en detrimento de la jurisdicción real y del regio patronato. ${ }^{67}$

No se ha hallado noticia documental alguna sobre Santa Marta con posterioridad a este litigio. Nada se sabe, por tanto, de su evolución, salvo que aún se mantenía en pie y funcionando como casa de corrección a fines del siglo XVIII, ${ }^{68}$ lo que nos hace pensar en su posible pervivencia hasta el fin del período colonial. En cualquier caso, no resulta aventurado suponer que su subsistencia debió de estar marcada por el agravamiento de sus deficiencias, la extrema necesidad económica y un continuo deterioro moral, ya que el propio carácter de la institución le haría especialmente vulnerable a los múltiples males que aquejaron a todo el distrito de Quito, pero especialmente a la capital y a los corregimientos centrales de Ambato, Latacunga y Ríobamba durante la segunda mitad del siglo XVIII.

La economía de la sierra, y en particular de la urbe quiteña, atraviesa entre 1765 y 1810 la etapa más crítica de toda la época colonial, por el total hundimiento de la industria textil, acelerado y agravado por la política reformista borbónica y la marginalidad en la que queda sumida la zona al cesar las ferias de Portobelo y tender a desplazarse hacia el sur el centro de las transacciones mercantiles. La intensidad sísmica registrada en los Andes centrales en este periodo y particularmente el terremoto de 1755 , de desastrosas con-

66 Ibídem, fols. 605v-608r.

67 Ibídem, 182, fols. 527-528.

68 Velasco, Historia del Reino de Quito, pág. 306. 
secuencias para todo el área de la capital, unida a las mortíferas oleadas epidémicas de 1759 y 1785, vendrían a acentuar las crisis de subsistencia y la explotación por los grupos dominantes de la población indígena, en la que tendieron a cebarse todas las catástrofes naturales. El malestar social que estas circunstancias provocaron se manifestó en una creciente inestabilidad, que desembocaría en diversos movimientos de subversión, como la "sublevación de los estancos" ocurrida en Quito en 1765, en cuya génesis estuvo involucrada la élite criolla, aunque su protagonismo recayó en los mestizos y castas, que constituían la base poblacional de los barrios de la capital, y en los indígenas de las localidades de su entorno, exasperados por la insoportable presión fiscal. ${ }^{69}$

En cuanto a los problemas jurisdiccionales planteados en torno al gobierno y ordenamiento del recogimiento de Santa Marta, es de suponer, habida cuenta de la política eclesiástica desarrollada por Fernando VI y sobre todo por Carlos III y Carlos IV, y su acentuado carácter regalista, que la balanza se iría inclinando cada vez más a favor de la autoridad civil y que lo que había comenzado siendo un centro de acogida y asistencia patrocinado por la caridad del obispo Solís y con un eminente carácter religioso, tras metamorfosearse en un centro de reclusión y castigo, terminase convertido en una cárcel de mujeres consentida y controlada por los representantes del poder civil, aunque sin alcanzar la categoría de prisión real, como ocurrió con el recogimiento mexicano de Santa María Magdalena. ${ }^{70}$

69 Ortiz de la Tabla, J.: Economía y sociedad en Quito (1765-1810), en La América española en la Epoca de las Luces, Madrid, 1988, págs. 183-199 y Velasco, Historia del Reino de Quito, págs. 322-330 y 334-338). Sobre esta rebelión han aparecido dos artículos: McFarlane, Anthony: The Rebellion of the Barrios: Urban Insurrection in Bourbon Quito. "Hispanic American Historical Review", n. ${ }^{\circ}$ 69, 2, 1989. Andrien, Kenneth: Economic Crisis, Taxes and the Quito Insurrection of 1765. "Past and Present", n. ${ }^{\circ} 129$, noviembre 1990.

70 Muriel, Los recogimientos de mujeres, págs. 110-144. 